\title{
The effect of gestures on second language memorisation by young children
}

\author{
Marion Tellier
}

Laboratoire Parole et Langage, Université de Provence, France

Corresponding author:

Marion Tellier

Université de Provence - Aix-Marseille I

Laboratoire LPL

29 av. R. Schuman

13621 Aix-en-Provence Cedex 1

France

Email: marion.tellier@|pl-aix.fr

\begin{abstract}
This article examines the impact of gesture on second language memorisation in teaching to very young learners. Twenty French children (mean age 5;5) took part in an experiment. They had to learn eight words in a foreign language (English). One group of children $(\mathrm{N}=10)$ were taught words with pictures and another group ( $\mathrm{N}=10)$ with accompanying gestures. Children in this group had to reproduce the gestures while repeating the words. Results show that gestures and especially their reproduction significantly influence the memorisation of second language (L2) lexical items as far as the active knowledge of the vocabulary is concerned (being able to produce words and not only understand them). This finding is consistent with theories on multimodal storage in memory. When reproduced, gestures not only act as a visual modality but also as a motor modality and thus leaves a richer trace in memory.
\end{abstract}

Keywords: teaching gestures, memorisation, second language acquisition, children 


\section{The effect of gestures on second language memorisation by young children}

Several studies have emphasised the role of gestures in second language (L2) acquisition (for an overview, see Gullberg, 2008). Teachers tend to gesture a lot (Sime, 2001; Hauge, 1999), especially when addressing young learners and/or beginners. It is commonly acknowledged that 'teaching gestures' (i.e. gestures used deliberately by teachers to help their students) capture attention and make the lesson more dynamic. Using analyses of video recordings of English lessons to French students, Tellier (2006) determined three main roles for teaching gestures: management of the class (to start/end an activity, question students, request silence, etc.), evaluation (to show a mistake, correct, congratulate, etc.) and explanation (give indications on syntax, underline specific prosody, explain new vocabulary, etc.). Teaching gestures appear in various shapes: hand gestures, facial expressions, pantomime, body movements, etc. They can either mime or symbolise something and they help learners to infer the meaning of a spoken word or expression, providing that they are unambiguous and easy to understand. This teaching strategy is thus relevant for comprehension (Tellier, 2006). However, its utiliy may depend on the kind of gesture used by the teacher. It has been highlighted that foreign emblems, for instance, may lead to misunderstandings when not known by the learners (Hauge, 1999; Sime, 2001).

In addition to supporting comprehension, teaching gestures may also be relevant for learmers' memorisation process. Indeed, many second language teachers who use gestures as a teaching strategy declare that they help learners in the process of memorising the second language lexicon. Many of them have noticed that learners can retrieve a word easily when the teacher produces the gesture associated with the lexical item during the lesson before them. Others have seen learners (especially young ones) spontaneously reproducing the gesture when saying the word. The effect of gestures on memorisation is thus something witnessed by many but hardly explored on a systematic and empirical basis.

\section{Multimodality and memorisation}

One of the universally acknowledged facts about memory in cognitive psychology is that it can be divided into three stores: the sensory, the short-term, and the long-term. Differences between theses types of memory are based both on the storage capacity and the retention of a piece of information (from a millisecond up to several years).

Short-term memory, now more commonly referred to as working memory, has been considered to be a very dynamic system. Baddeley (1990) identifies three components of working memory: (1) the Articulatory Loop which consists of a speech sound based storage system that can hold a limited quantity of phonological items; (2) the Visuo-Spatial Sketchpad which is related to visual imagery and which serves to encode non-verbal visual and spatial information; and (3) the Central Executive Device which controls the two other components and gives attention to incoming stimuli. It is also responsible for retrieving information from long term memory.

As far as learning is concerned, several researchers have been interested in how multimodality (the co-occurrence of several modalities) can reinforce memorisation. Clark \& Paivio's Dual Coding Theory (1991) suggests that learning is reinforced when both verbal and non-verbal modalities co-occur. Baddeley (1990) also argues that coding a piece of information through different modalities has an impact on memorisation because it leaves more traces in the memory system. Moreno \& Mayer (2000) argue that multimedia learning can be efficient because it conveys both auditory and visual information. Their cognitive theory of multimedia learning is based on the assumptions that working memory includes independent auditory and visual working memories and that humans have separate systems for representing verbal and non-verbal information, consistent with the Dual Coding Theory.

Furthermore, research in cognitive psychology has highlighted the effect of enactment and of the motor modality on memorisation. Recall of enacted action phrases has been found to be superior to 
recall of action phrases without enactment (Engelkamp \& Cohen, 1991; Cohen \& Otterbein, 1992). Engelkamp \& Zimmer (1985) demonstrated that the free recall of enacted sentences is superior to the recall of spoken sentences and to the recall of visually imaged sentences. Thus, the enactment effect is not a mere visual effect. Engelkamp \& Zimmer (1985) explain the enactment effect on memorisation by postulating a motor system above the visual and the verbal memory systems. It seems that the encoding of enacted events involves a verbal modality, a visual modality and a motor modality. Thus, enactment adds something to the memory trace of the event, it makes the trace richer, or more distinctive, and consequently easier to find at recall. Nyberg, Persson \& Nilsson (2002) have demonstrated the positive effect of enactment encoding on memorisation for different populations (including demented patients and patients with frontal-lobe dysfunction) and for different age groups ranging from 35 to 80 years of age.

Recent neuroimaging studies have also brought evidence that retrieval following enactment encoding is associated with motor brain regions (Nyberg et al., 2002). Brain activity is higher during cued recall after enacted encoding compared to cued recall after verbal encoding. The activated regions (contralateral somatosensory and motor cortex) are also more active during enacted encoding compared to verbal encoding, suggesting that some of the motor areas that are engaged during enactment are subsequently reactivated during retrieval.

\section{The effect of gestures on short term memorisation in the first language (L1)}

There has been very little work on the impact of gestures on short term and long term memorisation in general. Experiments by Cohen \& Otterbein (1992) have demonstrated that adult subjects exposed to sentences illustrated by pantomimic gestures ${ }^{1 i}$ remembered significantly more sentences than subjects who did not see the gestures and subjects who saw non-pantomimic gestures. They worked with three groups of adult subjects. The subjects had to watch a video containing several different sentences in their $\mathrm{L} 1$ and then to write down as many sentences as they could remember in a free recall task. Each group received the same verbal input but the videos were slightly different: one just presented the sentences, the second showed somebody illustrating each sentence with pantomimic gestures, and in the last video, sentences were accompanied by non-pantomimic (i.e. meaningless) gestures. A similar experiment set up by Feyereisen (1998) confirms Cohen \& Otterbein's results. Feyereisen hypothesised that a sentence accompanied by a gesture is better remembered either because the gesture constitutes a distinctive effect (the gesture adds some particularity to the sentence) or because the gesture conveys significant information related to the meaning of the sentence in a visual modality which is added to the verbal information (double coding theory). Similarly to Cohen \& Otterbein's study, Feyereisen exposed his subjects to three kinds of sentences: without gestures, with iconic gestures, and with iconic gestures that did not match the content of the sentences and thus looked meaningless. Feyereisen found that in the recall task, facilitation only occurred for the sentences that were presented with iconic gestures that matched the content. He thus inferred that higher recall scores do not depend on the increased distinctiveness of sentences presented together with meaningless gestures. The results highlight the effect of meaningful gestures and favour the hypothesis of the double coding theory and the impact of multimodality on memorisation of sentences in L1 by adult subjects.

Both studies (Cohen \& Otterbein, 1992 and Feyereisen, 1998) dealt only with adult subjects. In the experiments reported on here younger subjects have been tested. There has been no work on the effect of gestures on memorisation in children, whether in first or second languages, on short or on long term memorisation. In a series of studies the impact of gestures on memorisation has been explored (Tellier, 2005, 2006 and 2007) to examine whether gestures improve children's memory for words in the L1, taking into account the difference in mnemonic span between adults and children. The notion of mnemonic span is used here to refer to the number of items a subject can memorise from a list heard once. The average score is 7 items plus/minus 2 (Miller, 1956; Baddeley, 1990) for an adult. However, it 
is lower for children and increases with age and cognitive development (Cowan et al., 1991). Span for digits (the most frequent stimuli) exhibits roughly a threefold increase from the age of 2 to young adulthood (college). The mnemonic span is thus about 2 items at the age of 2, 4 items at the age of 5, 5 at the age of 7,6 items at the age of 9 and 7 at the age of 12 (Dempster, 1981).

A first study (Tellier, 2005) involved 32 French children (age range 4;11 to 5;10, $M$ 5;5) who were divided into 2 groups (control and experimental). They had to watch 3 videos (each contained a list of 10 words in the L1). The children watched the videos alone with the experimenter and had to do a free recall task immediately afterwards. The three videos watched by the control group only presented them with words pronounced by a person on the screen. The first video watched by the experimental group was the same as the control group, the second video was illustrated with gestures and the third with pictures. The experimental group had significantly better results with video 2 and 3 . This suggests that the use of visual modalities (pictures and gestures) improves short term memorisation in a free recall task, consistent with the Dual Coding Theory. The significant effect of pictures on young children's memory span is also consistent with previous findings (Cowan et al., 1991 who worked with 4 yearolds). Importantly, there was no statistical difference between the effect of the picture and of the gesture on memorisation. In this case, gestures acted as a mere visual modality since they were only looked at.

A second study (Tellier, 2007) examined whether reproducing gestures has a greater impact on children's' memory span than merely looking at them. 42 French children (age range 5;3 to 6;3, $M$ 5;9) performed a very similar task to the previous experiment except that images were not used and that children were asked to repeat the words out loud in their first language after listening to them. There were three groups for the study. A control group listened to the words and repeated them. A first experimental group (EG1) listened to the words and repeated them as well but also looked at illustrative gestures with each word. A second experimental (EG2) group was told to listen to the words, repeat them, look at the gestures and reproduce them. They were then given a free recall task. Results show that the second experimental group (EG2) did significantly better than the two other groups (control and EG1). This points to an effect of the reproduction of gestures on short term memorisation in the L1.

\section{The effect of gestures on memorisation in a second language (L2)}

As far as the effect of gestures on memorisation of items in second language is concerned, there have been very few studies. Allen (1995) worked with 112 American university students in French. A control group and a comparison group were shown 10 French sentences and their English equivalents on a screen and they also heard a teacher pronouncing them 3 times. The students were told to repeat them. The experimental group's procedure differed only in that the students were also provided with an illustrative gesture for each sentence, which they saw three times (with the three repetitions of the sentence) and had to reproduce. However, they did not repeat the sentences, only the gestures. Then, immediately after all 10 sequences, a post-test was given in which the teacher produced the 10 French sentences in a different order and during the pause after each sentence the subjects had to write down the English equivalent. The comparison group and the experimental group were given the gestures as well. There were 5 sessions of this kind with different groups of 10 French expressions. The results show that the students presented with illustrative gestures recalled more sentences than the others. The experimental group who reproduced the gestures did significantly better than the comparison group who only saw them during the post-test. The effect of reproducing gestures on memorisation in L2 by adult learners was confirmed.

Allen's pioneering experiment (1995) seems to be the only study on the impact of gestures on memorisation of L2 sentences. However, it has two limitations. First, the L2 sentences were always given to the subjects with the L1 translation, but the sentences to be memorised were French idiomatic expressions which are not always directly translatable. Second, subjects were asked during the posttest to give the L1 equivalent of the L2 sentences that were only used as stimuli. The study thus does not assess how many expressions in $\mathrm{L} 2$ subjects have remembered with gestures, but rather how many 
expressions they can translate. The experiment therefore dealt mainly with passive knowledge of the vocabulary, that is, the ability to recognise and translate but not to produce the L2 items. It is therefore not clear whether gestures affect active knowledge of L2 vocabulary. It is also not known whether gestures affect the memorisation of lexical items in L2 in child learners. The current study therefore examines precisely these issues.

\section{This study}

Hypothesis

This experiment builds on the findings of the two experiments mentioned earlier. First, it is assumed that gestures and pictures, when used as visual modalities, have a similar impact on memorisation (Tellier, 2005). Second, as demonstrated by Engelkamp \& Cohen (1991), Allen (1995) and Tellier (2007), reproduction of gestures has a stronger impact on short term memorisation than only viewing gestures.

The aim of this study is to examine whether this also holds for the learning of second language items and for long term memorisation. The assumption is that the combined use of a spoken modality, a visual modality, and a motor modality leaves a richer trace on memorisation (Engelkamp \& Cohen, 1991; Cohen and Otterbein, 1992 and Nyberg et al., 2002). Thus, seeing and reproducing gestures (visual and motor modality) should have a stronger impact on memorisation of items than simply seeing pictures (visual modality).

This study also aims to assess active knowledge on new vocabulary.

\section{Method}

Participants

Twenty French children took part in this experiment on long term memorisation (age range 4;11-5;10, $M$ 5;5, SD 3 months). They were divided randomly into two groups of 10: one picture group and one gesture group. Every child was monolingual (French native speaker), none of them knew English.

Materials

Eight English words were selected and associated with a picture and an illustrative gesture: 'house', 'swim', 'cry', 'snake', 'book', 'rabbit', 'scissors' and 'finger'. Since a child of 5 has a mnemonic span of about 4 items (Dempsey, 1981), and the memory span for a foreign language is reduced (Gaonac'h, 1995), we included only a small number of words. As we are dealing with long term memorisation and as the procedure of the experiment requires several sessions, we can expect children to remember more and more items after each session. To avoid floor or ceiling effects, eight items were chosen; not too many words to learn, which could discourage the child, but enough words to enable progression to be observed.

The lexical items chosen for this experiment were very common words for children likely to be taught in a second language course by to French Official instructions (Ministère de la Jeunesse, de l'Education Nationale et de la Recherche, 2002). They were also selected because they are easy to illustrate both with pictures and gestures. Two sets of experimental videos were developed with a presentation of the words and their visual equivalent. One video showed the words only with gestures and the other only with pictures. In each video, the lexical items were pronounced clearly and were followed by a blank of two seconds to let the children repeat the words. The presentation of the corresponding pictures or gestures slightly preceded the pronunciation of the words. The experimental video was also used in the assessments. All items were presented in the same order during training, but were presented in a different order during the assessments. The gestures were selected from recordings of English lessons to young French children. For instance, the gesture that represented 'book' was made by opening and closing hands, palms facing up, the gesture for 'swim' was a mime of the action of swimming (breaststroke) and the gesture for 'cry' consisted in drawing tears with a finger down the cheeks of a sad face.

Figures 1 to 6 show some of the gestures and pictures used as materials. 


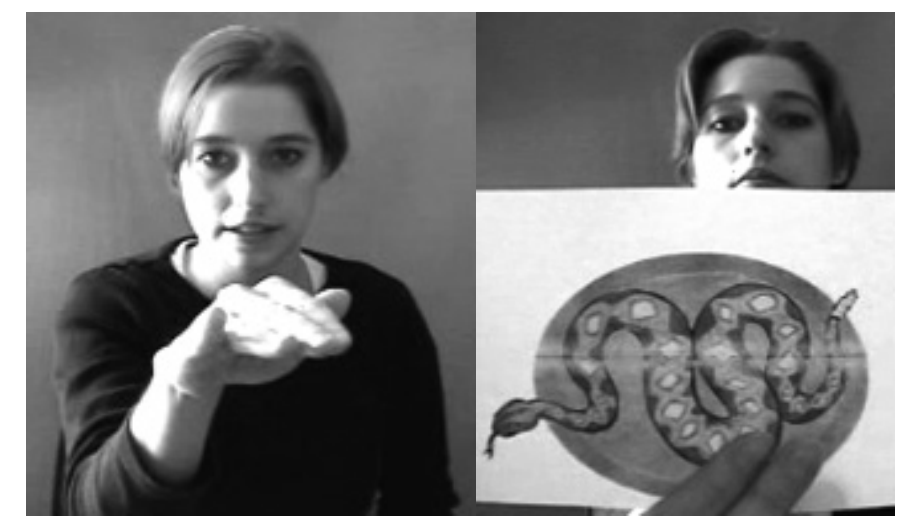

Figures 1 and 2. Snake

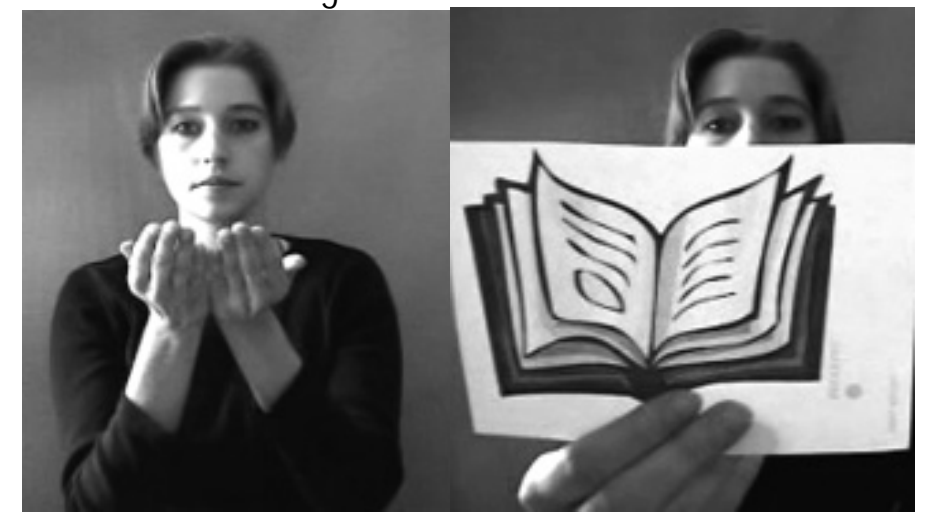

Figures 3 and 4. Book

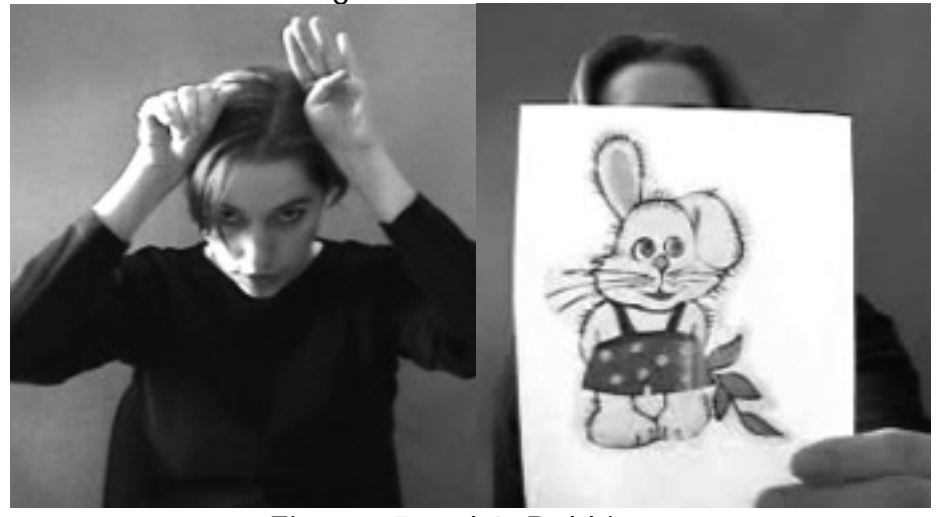

Figures 5 and 6 . Rabbit

\section{Procedure}

The study lasted 4 weeks with one session per week during which children watched the videos according to their group (picture or gesture). The videos were displayed on a laptop. Children were told that it was a game to learn English words. Children were tested individually.

Initially, every word was presented once with both the picture and the gesture, to make sure that the meaning was understood and that there was no ambiguity. For some children, especially the younger ones, the meaning of certain gestures and pictures may not be easy to detect and it seemed best to use several modalities to clarify the meaning of some words in the second language classroom (Tellier, 2006). Following that and for the rest of the experiment, the words were only presented with one additional modality (gesture or picture, depending on the group). During the first three sessions, the subjects were told to repeat the English words they heard 5 times (once during the first session and 
twice during Session 2 and 3). The children of the gesture group also had to reproduce the gestures while repeating the words. Every subject heard and repeated each word exactly the same number of times (i.e. 5 times) so that the children received the same input. Session 2 and Session 3 included an assessment. In Session 4, there was no warm-up of the items but only two assessments. In the first assessment (Session 2), the passive knowledge of the vocabulary was evaluated. Children heard the English words in a different order and had to show the associated picture or gesture depending on their group. In the second assessment (Session 3), they were shown the pictures or the gestures and had to produce the corresponding English word, which gave an evaluation of the active knowledge of the vocabulary. In the last assessment (Session 4), both previous assessments were conducted: first the evaluation of the active knowledge, followed by the passive knowledge of the lexical items. Table 1 sums up the procedure for each group.

\begin{tabular}{|c|c|c|c|c|}
\hline & SESSION 1 & SESSION 2 & SESSION 3 & SESSION 4 \\
\hline \multirow{2}{*}{ Picture group } & $\begin{array}{l}\text { 1.Double } \\
\text { presentation } \\
\text { Watch in silence }\end{array}$ & $\begin{array}{l}\text { 1. Listen and repeat } \\
\text { each word with video }\end{array}$ & $\begin{array}{l}\text { 1. Listen and repeat } \\
\text { each word with video }\end{array}$ & \multirow{2}{*}{ No rehearsal } \\
\hline & $\begin{array}{l}\text { 2. Listen and repeat } \\
\text { each word with video }\end{array}$ & $\begin{array}{l}\text { 2. Listen and repeat } \\
\text { each word with video }\end{array}$ & $\begin{array}{l}\text { 2. Listen and repeat } \\
\text { each word with video }\end{array}$ & \\
\hline \multirow{2}{*}{ Gesture group } & $\begin{array}{l}\text { 1.Double } \\
\text { presentation } \\
\text { Watch in silence }\end{array}$ & $\begin{array}{l}\text { 1. Listen and repeat } \\
\text { each word and each } \\
\text { gesture with video }\end{array}$ & $\begin{array}{l}\text { 1. Listen and repeat } \\
\text { each word and each } \\
\text { gesture with video }\end{array}$ & \multirow{2}{*}{ No rehearsal } \\
\hline & $\begin{array}{l}\text { 2. Listen and repeat } \\
\text { each word and each } \\
\text { gesture with video }\end{array}$ & $\begin{array}{l}\text { 2. Listen and repeat } \\
\text { each word and each } \\
\text { gesture with video }\end{array}$ & $\begin{array}{l}\text { 2. Listen and repeat } \\
\text { each word and each } \\
\text { gesture with video }\end{array}$ & \\
\hline \multirow{2}{*}{ Assessments } & \multirow{2}{*}{ none } & \multirow{2}{*}{$\begin{array}{l}\text { Show appropriate } \\
\text { picture or gesture }\end{array}$} & \multirow{2}{*}{$\begin{array}{l}\text { Produce the } \\
\text { appropriate word }\end{array}$} & a. As in Session 3 \\
\hline & & & & b. As in Session 2 \\
\hline
\end{tabular}

Table 1. Procedure

\section{Results}

The mean numbers of correctly memorised words per group and assessment session are summarised in Table 2.

\begin{tabular}{|c|c|c|c|c|}
\hline & $\begin{array}{c}\text { Assessment } 1 \\
\text { (passive) }\end{array}$ & $\begin{array}{l}\text { Assessment } 2 \\
\text { (active) }\end{array}$ & $\begin{array}{l}\text { Assessment 3a } \\
\text { (active) }\end{array}$ & $\begin{array}{l}\text { Assessment 3b } \\
\text { (passive) }\end{array}$ \\
\hline Picture group & 3 & 2.6 & 2.8 & 4.3 \\
\hline Gesture group & 3.1 & 3.7 & 3.8 & 4.9 \\
\hline $\begin{array}{l}\text { Difference } \\
\text { (T-tests) }\end{array}$ & $x$ & $\begin{array}{c}t(18)=-2.108 \text { with } p< \\
.0493\end{array}$ & $\begin{array}{c}t(18)=-2.433 \text { with } \\
p<.0256\end{array}$ & $\begin{array}{c}t(18)=-1,579 \text { with } \\
p<.1318\end{array}$ \\
\hline
\end{tabular}

Table 2. Means of memorised words for each group per assessment

First assessment (Session 2)

In this assessment, the aim was to measure the passive knowledge of the vocabulary, i.e. whether children were able to show the visual equivalents of the words. The subjects of the picture group were shown the pictures and were asked to point to the corresponding one when they heard an English word. The subjects of the gesture group had to produce the appropriate gesture. Note that the task was more difficult for the children of the gesture group since the subjects of the picture group had to choose among a limited number of pictures in front of them, whereas children of the gesture group had to remember the gestures they had learnt. 
Despite the asymmetry in the difficulty of the task, children of both groups performed equally (cf. Table 2). The subjects of the picture group gave a mean of 3 good answers (range 1-6, SD 1.3 word) and in the gesture group a mean of 3.1 (range 1-5, SD 1.4). Four words were better memorised than others: 'scissors' (19/20 children), 'rabbit' (10/20 children), 'cry' (10/20 children) and 'finger' (9/20 children). It is noticeable that among those 4 words are three disyllabic words.

\section{Second assessment (Session 3)}

In the second assessment, the aim was to measure the active knowledge of the vocabulary, that is to say, whether children were able to produce the English words. For this assessment, they saw pictures or gestures in a different order than the one of the repetitions and had to name them.

The picture group gave a mean of 2.6 correct words (range 1-5, SD 1.17 word) and the gesture group 3.7 words (range. 2-5, SD 1.16 word). The difference between the means of answers of both groups was thus 1.1 word. An independent samples $t$-test (cf. Table 2) confirmed that this difference was significant and revealed the effect of the reproduction of gestures on memorisation.

\section{Third assessment (Session 4)}

This last assessment was concerned with long term memorisation since no rehearsal of the items was provided during the session. Therefore, children had not heard the words for a whole week when they were assessed.

The picture group gave a mean of 2.8 correct answers (range 2-4, SD 0.919) and the gesture group a mean of 3.8 good answers (range 2-5, SD 0.919). The difference in performance was thus of 1 word. An independent samples t-test showed that this difference was significant (cf. Table 2). Therefore, there was an effect of the reproduction of gestures on long term memorisation. The best memorised words are 'scissors' (20/20 children), 'book' (16/20 children), 'rabbit' (10/20 children), 'cry' and 'finger' (7/20 children).

As far as the passive knowledge of the vocabulary was concerned in this last assessment, there was no real difference of performance. Children in the picture group correctly paired 4.3 words (range 3$5, S D$ 0.823) with the appropriate picture, and children in the gesture group correctly paired 4.9 words (range 4-6, SD 0.876) with their gestures. An independent samples t-test showed that the difference was not significant (cf. Table 2).

\section{Memorisation of the items}

During all the assessments, 5 items were successfully memorised more often than the others: 'finger', 'cry', 'rabbit', 'book' and 'scissors'. Figures 7 and 8 show the frequency of correct answers given for each word for the passive and for the active knowledge assessments. How can we explain that some L2 lexical items are easier to memorise than others (such as 'house' and 'swim')? One possibility is that syllabic structure matters. Among those 5 words are the only three disyllabic words of the list. Regarding the item 'scissors', this word may have sounded familiar to some children since the French equivalent is 'ciseaux', a phonologically similar form. Furthermore, during the repetitions of the items, 'scissors' was always the last one of the list and this may have led to a recency effect (Baddeley, 1990). 

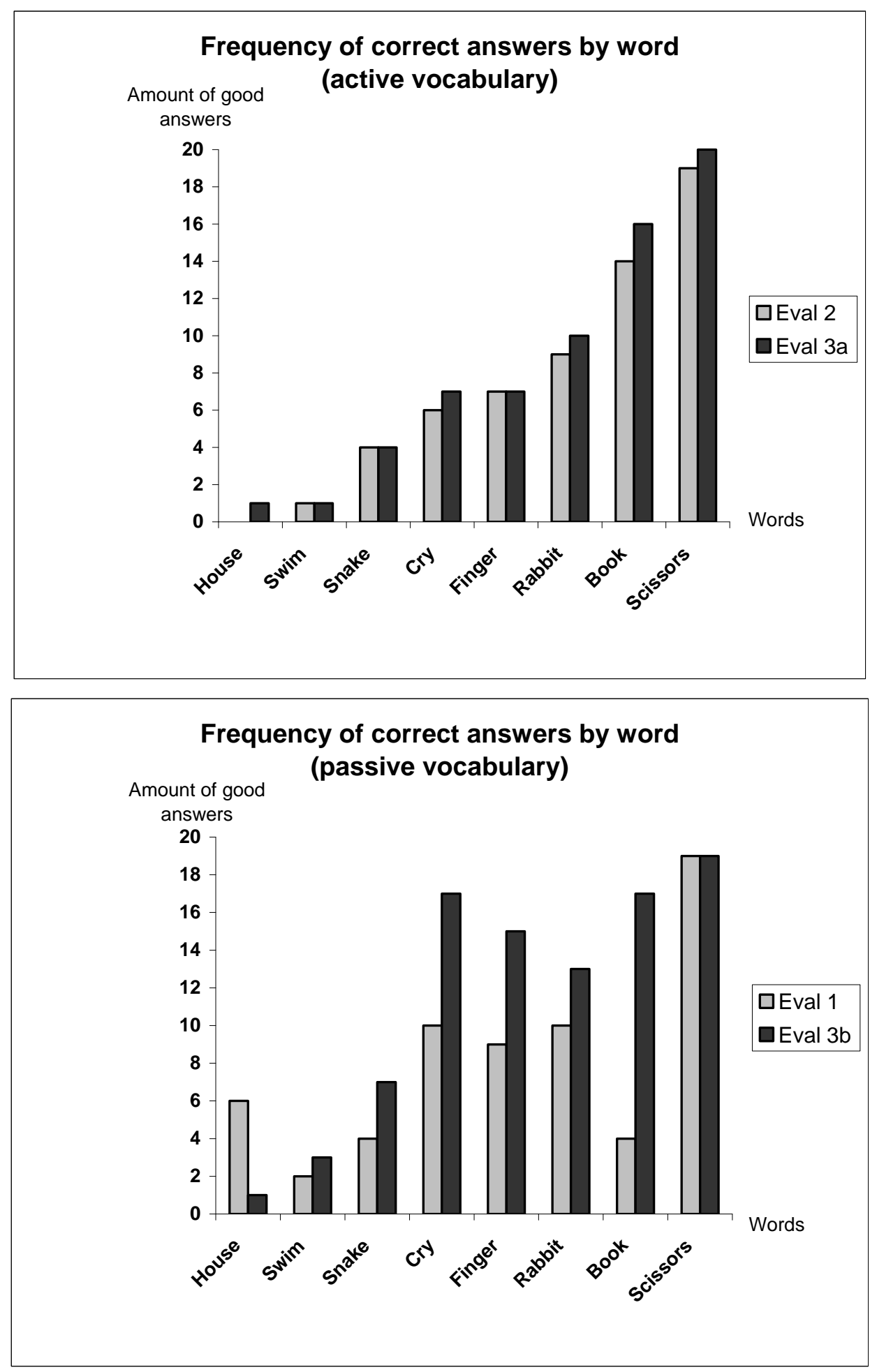

Figures 7-8. Frequency of correct answers by word

\section{Discussion}

The present study aimed to examine the effect of gesture reproduction on the long-term memorisation of L2 vocabulary in children. As hypothesised, the gesture group did significantly better than the picture group at least in the assessments measuring the active knowledge of the vocabulary. It appears that when gestures are re-produced and act as a motor modality, they have a stronger impact on memorisation than pictures (a visual modality). This result is consistent with previous studies 
(Engelkamp \& Cohen, 1991; Cohen \& Otterbein, 1992 and Nyberg et al., 2002) which have shown that enactment makes the trace in memory richer and facilitates recall. This is an important fact for teachers who want to help their young learners to acquire a second language. Involving the body in the learning process is therefore relevant in the classroom.

However, the results of the current study have to be treated with caution due to the limited number of subjects involved in the study ( $\mathrm{N}=20$ split into two groups of 10$)$. The experiment should be replicated with a larger sample of children. It could also be relevant to examine children of different age groups to investigate whether the effect of the reproduction of gestures is valid for learners at all ages.

In addition, the scores of the learners are rather low; the gesture group only memorised 3.8 words out of 8 after the last session. This can be explained by the fact that the words have only been repeated 5 times and have been learnt in a controlled experimental setting. Learning vocabulary in a classroom is obviously very different from what is done in an experiment. Indeed, the input is much more important in class and so is the amount of repetitions. Also, unlike in the experiment, children have opportunities to use the new vocabulary in various ways while in class in stories, games, songs and other activities.

For future work it seems relevant to study different kinds of words. There may be a difference in the memorisation of words depending on word class. It has been suggested that verbs are harder to learn than nouns (see Gentner, 1981, for an overview). However, Choi \& Gopnik (1995) investigated children's early lexical development in English and Korean, and compared caregivers' linguistic input in both languages. They found that very young Korean children use verbs productively with appropriate inflections and that, for most of them, the verb spurt occurs before the noun spurt. Unlike in English, both verbs and nouns in Korean are dominant categories from the single-word stage. By comparing the verbal input received by children of both linguistic groups, Choi and Gopnik (1995) found that Korean caregivers used more verbs and fewer nouns than the American mothers. The study suggests that verbs are accessible to children from the beginning, and that they may be acquired early in children who are encouraged to do so by their language-specific grammar and input.

Even if the findings in the literature in this domain are somewhat contradictory, it would nevertheless be interesting to assess the impact of gestures on the memorisation of nouns and verbs in second language acquisition. For instance, one may wonder whether or not action verbs are easier to memorise with gestures than nouns.

Moreover, it would be interesting to further examine the syllable as a variable by testing monosyllabic as well as di- or even polysyllabic words. Indeed, the three disyllabic words in our study were among the best memorised items. It is difficult to know whether this is due to a word duration effect or not. The literature on memory span generally suggests that lists made up of long words are harder to recall than lists of short words. Baddeley, Thomson \& Buchanan (1975) found a significant effect of the word length on immediate serial recall. They showed that this effect was due to articulatory duration by selecting two sets of disyllabic words, which were matched for frequency and number of phonemes but which differed in terms of their articulatory duration. In tests of immediate serial recall the lists made from words with a short articulatory duration were better recalled than those made from long words. Similarly, Lovatt et al. (2000) also conducted a series of experiments to compare immediate serial recall of disyllabic words that differed on spoken duration. They first found that long words were better recalled than short words. However, in a second experiment using another set of items, they found no difference between long and short disyllabic words. Finally, in a third experiment using the word set originally selected by Baddeley, Thomson \& Buchanan (1975), they confirmed the large advantage for shortduration words. Lovatt et al. (2000) suggest that there is no reliable advantage for short-duration disyllables in span tasks, and that previous accounts of a word-length effect in disyllables are based on accidental differences between list items. It seems that more data on this topic is needed.

Another explanation for why some words are better memorised than others may be because they sound more distinctive or more pleasant to the children. In a study on the effect of multimodality 
(especially pictures) on the memorisation of $L 2$ lexical items, Dat (2006) found that a long item such as 'coconut tree' was among the better memorised words of her study. The effect of distinctiveness of some words on memorisation should be investigated in the SLA field. In a more global perspective, the impact of prosody on second language learning requires more attention particularly in the L2 classroom.

To conclude, this study has shown that gesturing enables children to memorise vocabulary better in L2, as they get physically involved in their learning. The findings support Paivio's Dual Coding Theory, which argues that a verbal and a visual modality reinforce memorisation. This study goes one step further, showing that gestures - a motor modality - leave an even richer trace in memory.

\section{REFERENCES}

Allen, Linda Q. (1995). The effects of emblematic gestures on the development and access of mental representations of French expressions. The Modern Language Journal, 79, 521-529.

Baddeley, Alan (1990). Human memory: Theory and practice. East Sussex: Lawrence Erlbaum Associates Ltd. Publishers.

Baddeley, Alan, Neil Thompson \& Mary Buchanan (1975). Word Length and the Structure of Memory. Journal of Verbal Learning and Verbal Behaviour, 14, 575-589.

Choi, Soonja \& Alison Gopnik (1995). Early acquisition of verbs in Korean: A cross-linguistic study. Journal of child language, 22 (3), 497-529.

Clark, James M. \& Allan Paivio (1991). Dual Coding Theory and Education. Educational Psychology Review, 3 (3), 149-210.

Cohen, Ronald L. \& Nicola Otterbein (1992). The mnemonic Effect of speech Gestures: Pantomimic and Non-Pantomimic Gestures compared. European Journal of Cognitive Psychology, 4 (2), 113-139.

Cowan, Nelson, J. Scott Saults, Carrie Winterowd \& Molly Sherk (1991). Enhancement of 4-year-old children's memory span for phonologically similar and dissimilar word lists. Journal of experimental child psychology, 51, 30-52.

Dat, Marie-Ange (2006). Didactique présecondaire des langues étrangères: l'influence de la présentation multimodale du lexique sur la mémorisation chez des enfants de 8 à 11 ans. Unpublished Doctoral Dissertation, University of Toulouse 2-Le Mirail.

Dempster, Franck N. (1981). Memory span: Sources of individual and developmental differences. Psychological Bulletin, 89, 63-100.

Engelkamp, Johannes \& Hubert D. Zimmer (1985). Motor programs and their relation to semantic memory. German Journal of Psychology, 9, 239-254.

Engelkamp, Johannes \& Ronald L. Cohen (1991). Current issues in memory of action events. Psychological Research, 53, 175-182.

Feyereisen, Pierre (1998). Le rôle des gestes dans la mémorisation d'énoncés oraux. In Santi, Serge, Isabelle Guaiitella, Christian Cavé \& Gabrielle Konopczynski (Eds.), Oralité et gestualité. Communication multimodale, interaction. Actes du colloque Orage 98 (pp. 355-360). Paris: L'Harmattan.

Gaonac'h, Daniel (1995). La mémoire dans l'apprentissage des langues vivantes: fonctionnement, acquisitions, utilisation. Les langues modernes, 2, 9-24.

Gentner, Dedre (1981). Some interesting differences between verbs and nouns. Cognition and Brain Memory, 4 (2), 161-178. 
Gullberg, Marianne (2008). Gestures and second language acquisition. In Nick C. Ellis \& Peter Robinson (Eds.), Handbook of cognitive linguistics and second language acquisition (pp. 276305). London: Routledge.

Hauge, Elizabeth (1999). Some common emblems used by British English teachers in EFL classes. In Killick, David \& Margaret Parry (Eds.), Cross-cultural Capability - Promoting the Discipline: Marking Boundaries and Crossing Borders Proceedings of the conference at Leeds Metropolitan University Dec. 1998, pp. 405-420.

Lovatt, Peter, S.E. Avons \& Jackie Masterson (2000). The Word-length Effect and Disyllabic Words. The Quaterly Journal of Experimental Psychology, 53a (1), 1-22.

Miller, George A. (1956). The magical number seven, plus or minus two: Some limits on our capacity for processing information. Psychological Review, 63, 81-97.

Ministère de la Jeunesse, de l'Education Nationale et de la Recherche. (2002) Programme des langues étrangères et régionales à l'école primaire. B.O.E.N. hors série n 4 du 29 août 2002.

Moreno, Roxanna \& Richard E. Mayer (2000). A Learner-Centered Approach to Multimedia Explanations: Deriving Instructional Design Principles from Cognitive Theory. Interactive Multimedia Electronic Journal of Computer Enhanced Learning, 2 (2) http: //imej.wfu.edu.

Nyberg, Lars, Jonas Persson \& Lars-Göran Nilsson (2002). Individual differences in memory enhancement by encoding enactment: Relationships to adult age and biological factors. Neuroscience and Biobehavioral Reviews, 26, 835-839

Sime, Daniela (2001). The use and perception of illustrators in the foreign language classroom. In Cavé, Christian, Isabelle Guaïtella, \& Serge Santi (Eds.) Oralité et gestualité. Interactions et comportements multimodaux dans la communication (pp. 582-585). Paris: L'Harmattan.

Tellier, Marion (2005). L'utilisation des gestes en classe de langue: comment évaluer leur effet sur la mémorisation du lexique? In Billières, Michel, Pascal Gaillard, \& Nathalie Spanghero-Gaillard (Eds.) Actes du Premier colloque international de Didactique Cognitive: DIDCOG 2005. Université de Toulouse-Le Mirail, 26-28 Janvier 2005. Proceedings on CD-Rom.

Tellier, Marion (2006). L'impact du geste pédagogique sur l'enseignement-apprentissage des étrangères: Etude sur des enfants de 5 ans. Unpublished Doctoral Dissertation. University Paris 7 - Denis Diderot, Paris.

Tellier, Marion (2007). How do teacher's gestures help young children in second language acquisition? Proceedings of the meeting of International Society of Gesture Studies, ISGS 2005: Interacting Bodies, June, 15th-18 ${ }^{\text {th }}$, ENS Lyon, France. http://gesture-lyon2005.ensIsh.fr/IMG/pdf/TellierFINAL.pdf

Author note

Marion Tellier received her PhD in Linguistics in 2006 at University Paris 7 - Denis Diderot. She has since conducted research on embodided conversational agents at the IUT de Montreuil, University Paris 8, and is Maître de Conférence at the University of Provence - Aix-Marseille I. Her research interests include 'teaching gestures', second language teaching to children, teachers' training and gesture perception and recognition.

Notes

\footnotetext{
i The words « pantomimic » and « non pantomimic » are used by Cohen and Otterbein (1992).

Pantomimic gestures are mime-like gestures that represent speech whereas non pantomimic gestures have no semantic connexion with the speech they accompany: they are meaningless movements.
} 